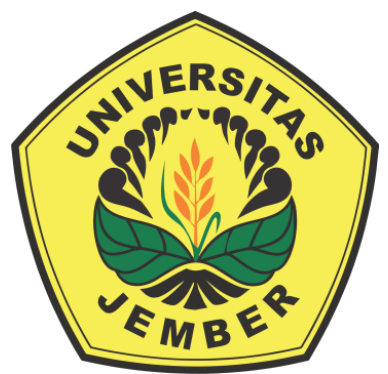

PENGEMBANGAN BAHAN AJAR OLIMPIADE MATEMATIKA BERDASARKAN MODEL PEMECAHAN MASALAH UNTUK MENINGKATKAN KEMAMPUAN PENALARAN MATEMATIS SISWA

TESIS

Oleh

MOHAMMAD TOHIR, S.Pd.

NIM 160220101001

PROGRAM STUDI MAGISTER PENDIDIKAN MATEMATIKA

FAKULTAS KEGURUAN DAN ILMU PENDIDIKAN

UNIVERSITAS JEMBER

2017 


\title{
Pengembangan Bahan Ajar Olimpiade Matematika Berdasarkan Model Pemecahan Masalah untuk Meningkatkan Kemampuan Penalaran Matematis Siswa
}

\author{
Mohammad Tohir \\ NIM: 160220101001 \\ Program Studi Magister Pendidikan Matematika Universitas Jember.
}

\section{Description:}

Penelitian pengembangan ini dilatari oleh pertimbangan adanya tuntutan untuk mencapai kondisi ideal dalam pembinaan olimpiade matematika, yaitu menyediakan bahan ajar olimpiade matematika yang mampu memfasilitasi siswa dalam belajar olimpiade matematika sesuai dengan karakteristik siswa (kemampuan penalaran matematis siswa) dan karakteristik materi olimpiade matematika. Setelah bahan ajar dinyatakan valid oleh para validator, kemudian dilakukan analisis lanjutan untuk mengetahui ketercapaian dan tingkat penalaran matematis siswa dalam memecahkan masalah olimpiade matematika. Pemecahan masalah yang digunakan merupakan pemecahan masalah yang dikembangkan oleh penulis berdasarkan model-model pemecahan yang sudah ada menjadi pemecahan masalah model baru, yaitu pemecahan masalah model M. Tohir.

Kemudian, pada tahap awal penyebaran yang dilakukan terbatas, yaitu diberikan kepada guru pembina olimpiade matematika di SMP Negeri 2 Jember, diterapkan kepada pada pelatihan/worskhop Guru-guru pembina olimpiade matematika di beberapa Kabupaten/Kota Provinsi Jawa Timur, dan dilakukan uji coba kepada siswa kelas VIIC SMPN 2 Jember dan Siswa Kelas VIII MTs. Raudlatul Hasanah Pamekasan. Hasil uji coba yang dilakukan kepada siswa, menunjukkan bahwa semua siswa sangat senang dan antusias dengan pembelajaran model pemecahan masalah tersebut.

\section{Disciplines:}

Pengembangan,

Bahan Ajar,

Buku,

Buku Guru,

Buku Siswa,

Olimpiade Matematika,

Penalaran Matematis Siswa,

Model Pemecahan Masalah,

Pemecahan Masalah Model M.Tohir.

Citation: Tohir, Mohammad. (2017). Pengembangan Bahan Ajar Olimpiade Matematika Berdasarkan Model Pemecahan Masalah untuk Meningkatkan Kemampuan Penalaran Matematis Siswa. Tesis. Magister Pendidikan Matematika Universitas Jember. Jember: Program Pascasarjana Universitas Jember. 


\section{DAFTAR PUSTAKA}

Afgani D., Jarnawi. (2011). Materi Pokok Analisis Kurikulum Matematika. Universitas Terbuka, Jakarta.

Ainun, Nur. (2015). Peningkatan Kemampuan Penalaran Matematis Siswa Madrasah Aliyah Melaluo Model Pembelajaran Mooperatif Tipe Teams Games Tournament. Jurnal Peluang. Volume 4, Nomor 1, Oktober 2015, ISSN: 2302-5158.

Angel. (2008). Instructional Design in ANGEL. Indianapolis: ANGEL Learning, Inc.

Arikunto, Suharsimi. (2013). Dasar-Dasar Evaluasi Pendidikan. Jakarta: Bumi Aksara.

Arif, Saiful. (2006). Olimpiade Matematika: Program Pembinaan Pengembangan Peningkatan Mutu Pendidikan Tingkat SMP. Science Center: Institut Teknologi Sepuluh Nopember Surabaya.

Astawa, I W. P. (2007). Model Pembinaan Olimpiade matematika Sekolah Dasar di Propinsi Bali. Jurnal Pendidikan dan Pengajaran UNDIKSHA. No 2. ISSN: 0215 - 8250. Bali.

Bani, A. (2011). Meningkatkan Kemampuan Pemahaman dan penalaran Matematis Siswa Sekolah Menengah Pertama Melalui Penemuan Terbimbing. (Online), (http://jurnal.upi.edu/file/2-Asmar_Bani.pdf), diakses 03 November 2017.

Bellanca, James. (2010). Enriched Learning Project. Bloomington: Solution Tree Press. Terjemahan oleh Ririn Sjafriani. 2012. Proyek Pembelajaran Yang Diperkaya. Jakarta: PT Indeks Permata Puri Media.

Bergqvist, Tomas dkk. (2011). Mathematical Reasoning in Teachers' Presentations. The Journal of Mathematical Behavior, Volume 31, Issue 2, June 2012, Pages 252-269.

Bieda, K. N. dkk. (2012). Reasoning-and-proving opportunities in elementary mathematics textbooks. International Journal of Educational Research, Volume 64, 2014, Pages 71-80.

Bin, X. Yee, L. P. (2007). Mathematical Olympiad in China: Problem and Solutions. World Scientific. East China Normal. University Press.

Branzei, Dan, dkk. (2003). Junior Balkan Mathematical Olympiads. Published and distributed by Plus Publisging House.

Carson, Jamin. (2007). A Problem With Problem Solving:Teaching Thinking Without Teaching Knowledge. The Mathematics Educator, Vol. 17, No. 2, 2007, Pages 7-14

Charles, R. (1982). Teaching Problem Solving: What, Why \&How. Dale Seymour Publications

Dahar, R.W. (1991). Teori-teori Belajar. Jakarta: Erlangga.

Daldiyono. (2006). Bagaimana Dokter Berpikir dan Bekerja. Jakarta: Gramedia Pustaka Utama.

Depdiknas. (2008). Panduan pengembangan bahan ajar. Jakarta: Direktorat Pembinaan Sekolah Menengah Atas Dirjen manajemen Pendidikan dasar dan menengah Depdiknas. 
Dewi, Siyami I. K. (2014). Analisis Kesalahan Siswa Kelas VIII dalam Menyelesaikan Soal pada Materi Faktorisasi Bentuk Aljabar SMP Negeri 1 Kamal Semester Genap Tahun Ajaran 2013/2014. MATHEdunesa: Jurnal Ilmiah Pendidikan Matematika. Volume 3 No 2. Unesa. Surabaya.

Ekawati, Estina \& Sumaryanta. (2011). Pengembangan Instrumen Penilaian Pembelajaran Matematika SD/SMP. Modul Matematika SD/SMP Program BERMUTU. PPPTK Matematika. Yokyakarta.

Eko P. W., S. (2009). Evaluasi Program Pembelajaran.Yogyakarta ; Pustaka Belajar.

Ellison, Glenn dan Swanson, Ashley. (2010). The Gender Gap in Secondary School Mathematics at High Achievement Levels: Evidence from the American Mathematics Competitions. Journal of Economic Perspectives.Vol 24, No 2. Halaman 109-128. American Economic Association. Massachustte Institute of Technolgy.

Engel, Arthur. (1997). Problem Books In Mathematics: Problem-Solving Strategies. Springer: New York, Berlin, Heidelberg, barcelona, Hong Kong, Londong, Milan, Paris, Singapore, Tokyo.

Fadjar. (2005). Materi Pembinaan Matematika SMP di Daerah. Yogyakarta: Depdiknas.

Fannie RD, Rohati. (2014). Pengembangan Lembar kerja Siswa (LKS) berbasis POE (Predict, Observe, Explain) pada Materi Program Linear Kelas XII SMA. Jurnal Sainmatika Vol 8 No 1. ISSN 1979-0910

Hake, R.R. (1999). Analizing Change.Gain Scores. Dept. of Physics, Indiana University. 24245 Hatteras Street, Woodland Hills, CA, 91367 USA

Hamalik, Oemar. (2011). Proses Belajar Mengajar. Jakarta: Bumi Aksara.

Hayati, L., (2013). Makalah: Pembelajaran Pendidikan Matematika Realistik Untuk Mengembangkan Kemampuan Berpikir Aljabar Siswa. Seminar Nasional Matematika dan Pendidikan Matematika FMIPA UNY Yogyakarta, 9 November 2013. ISBN : $978-979-16353-9-4$

Hermanto, Eddy. (2011). Diktat Pembinaan Olimpiade Matematika Materi Dasar. Bengkulu. http://baktiolimpiade.wordpress.com. [diunduh tanggal 7 Mei 2017].

Hudojo, H. (2005). Pengembangan Kurikulum dan Pembelajaran Matematika. Malang: Penerbit Universitas Negeri Malang.

Hobri. (2010). Metodologi Penelitian Pengembangan (Aplikasi Pada Penelitian Pendidikan Matematika). Jember: Pena Salsabila, cetakan I.

IEEE. (2001). Reference Guide for Instructional Design and Development. (Online), https://akronitmastersdigitalresources.wikispaces.com/file/view/IEEE.pdf/1775362 33/IEEE.pdf. Diakses 11 Desember 2017

Jailani. (2011). Pengembangan Perangkat Pembelajaran Matematika oleh Pendidik. Prosiding disajikan dalam Seminar Nasional Matematika dan Pendidikan Matematika, Jurusan pendidikan Matematika FMIPA UNY, Yogyakarta, 3 Desember 2011 
Jiagu, Xu. (2010). Lecture Notes on Mathematical Olimpiad Courses: Mathematical Olympiad Series. For Junior Section Vol. 1 dan 2. World Scientific Publishing Co. Pte. Ltd.

Jonsson, Bert. (2014). Learning Mathematics Through Algorithmic and Creative Reasoning. The Journal of Mathematical Behavior, Volume 36, December 2014, Pages 20-32.

Jumiati, dkk. (2013). Implementasi Pendekatan Pemecahan Masalah untuk Meningkatkan Kemampuan Berpikir Kreatif dan Penalaran Matematis Siswa SMP. Jurnal Peluang, Volume 2, Nomor 1, Oktober 2013, ISSN: 2302-5158

Gay, L.R. (1991). Educational Evaluation and Measurement: Competencies for Analysis and Application. Second edition. New York: Macmillan Publishing Compan.

Kadir, P. (2010). Penerapan Pembelajaran Kontekstual Berbasis Potensi Pesisir Sebagai Upaya Peningkatan Kemampuan Pemecahan Masalah, Komunikasi Matematik, dan Keterampilan Sosial Siswa SMP. Disertasi UPI. Bandung: Tidak diterbitkan.

Kausar. (2014). Pengaruh Penerapan Metode Pembelajaran Guru Yang Bervariasi Terhadap Peningkatan Hasil Belajar Siswa Kelas XI SMA Negeri 1 Labuhanhaji Timur Kabupaten Aceh Selatan. Jurnal Genta Mulia, Volume V. Nomor 2. Juli-Desember 2014, hlm. 72-85

Kemdikbud. (2017). Silabus Olimpiade Sains Nasional Sekolah Menengah Pertama. Jakarta.

Kemdikbud. (2015). Materi Pelatihan Guru Implementasi Kurikulum 2013 Jenjang SMP Tahun 2015. Jakarta.

Kurniawan dkk. 2007. Siap Juara Olimpiade Matematika SMP. Erlangga. Jakarta: PT Gelora Aksara Pratama.

Matondang, Zulkifli. (2009). Validitas dan Realibitas Suatu Instrumen Penelitian. Jurnal Tabularasa PPS UNIMED. Vol.6 No.1, Juni 2009. Medan

Mairing, J. P, Budayasa, I K, dan Juniati, Dwi. (2011). Profil Pemecahan Masalah Siswa Peraih Medali OSN Matematika. Jurnal Pendidikan dan Pembelajaran. vol 16, nomor 1, April 2011. Surabaya.

Mairing, J. P, Budayasa, I K, dan Juniati, Dwi. (2012). Perbedaan Profil Pemecahan Masalah Peraih Medali OSN Matematika Berdasarkan Jenis Kelamin. Jurnal Ilmu Pendidikan, Jilid 18, Nomor 2, Desember 2012, hlm. 125-134

Manik, F. Suseno. (2006). Pendidikan di Indonesia: Masalah dan Solusinya. Retrieved 9 Mei 2006 dari http://www.mii.fmipa.ugm.ac.id.

Marzuki, Ahmad. (2006). Implementasi Pembelajaran Kooperatif dalam Upaya Meningkatkan Kemampuan Koneksi dan Pemecahan Masalah Matematik Siswa. Tesis UPI Bandung.

Mahsup, M. (2010). Penerapan Strategi Investigasi Untuk Meningkatkan Pemahaman Tentang Sistem Persamaan Linier (SPL) Dua Variabel Di SMPN 5 Kepanjen Malang. Disertasi. UM Malang, hal.15.

Muchlis, A. (2003). Olimpiade Matematika Sekolah Dasar. Makalah disampaikan pada rakor Direktorat TK SD di Banjarmasin Kalimantan Selatan Naskah Undang-undang No. 20 tahun 2003 tentang Sistem Pendidikan Nasional. 
Mukhtar. (2013). Pengembangan Bahan Ajar Matematika Berbasis Masalah untuk Memfasilitasi Pencapaian Kemampuan Penalaran dan Pemahaman Konsep Siswa. Prosiding Semirata FMIPA Universitas Lampung

Mulyasa, E. (2006). Kurikulum Tingkat Satuan Pendidikan. Bandung: Remaja Rosdakarya.

Murtikusuma, Randi P. 2016. Pengembangan Lembar Kerja Siswa Matematika Model Problem-Based Leraning untuk SMK Perkebunan Bertemakan Kopi dan Kakao. Pancaran Pendidikan, 5(4), 51-60.

Nataliasari, Ike. (2014). Penggunaan Model Pembelajaran Kooperatif Tipe Think Pair Share (TPS) Untuk Meningkatkan Kemampuan Penalaran dan Pemecahan Masalah Matematis Siswa MTs. Jurnal Pendidikan dan Keguruan Vol. 1 No. 1, 2014, artikel 3.

Novandi, Mukhlis., Firmansyah. (2016). Pengembangan Bahan Ajar Matematika Berbasis pemecahan Masalah untuk meningkatkan Kemampuan Penalaran dan Koneksi Matematis Siswa SMP. Jurnal Penelitian Pendidikan MIPA. Vol. 1 No. 1 April, Th. 2016

Panen, P., dan Purwanto. (2004). Penulisan Bahan Ajar. Jakarta: Ditjen Dikti Depdikbud.

Parta, I Nengah. (2009). Pengembangan Model Pembelajaran Inquiri Untuk Memperhalus Pengetahuan Matematika Mahasiswa Calon Guru Melalui Pengajuan Pertanyaan. Disertasi. Tidak dipublikasikan.

Prianto, Agus. (2015). Kajian Materi Aljabar dan Komunikasi Matematis. Indonesian Digital Journal of Mathematics and Education Volume 2 Nomor 2 Tahun 2015, hlm. 115122. ISSN 2407-8530.

Purwanto, Ngalim. (2012). Prinsip-Prinsip dan Teknik Evaluasi Pengajaran. Bandung: PT. Remaja Rosdakarya

Polya, G. (1985). How to Solve it. A New Aspect of Mathematical Method. New Jersey: Princeton University Press.

Rahmat, Adi. (2007). Pengembangan dan Peningkatan Kualitas Pembelajaran (Penelitian Berorientasi Peningkatan Kualitas Pembelajaran). LPP Universitas Muhammadiyah

Rasyidin, L.F, Maulana F. (2008). Cara Mudah Menaklukkan Olimpiade Matematika SMP. Jakarta: Wahyu Media. ISBN: 9797951669. ISBN13: 9789797951665.

Ruseffendi, H.E.T. (1991). Pengantar Kepada Membantu Guru Mengembangkan Kompetensinya dalam Mengajar Matematika untuk Meningkatkan CBSA. Bandung: Tarsito.

Rizal, Muh. (2011). Pengembangan Perangkat Pembelajaran Estimasi Berhitung Di Sekolah Dasar. Prosiding disajikan dalam Seminar Nasional Penelitian Pendidikan dan Penerapan MIPA, Fakultas MIPA UNY, Yogyakarta, 14 Mei 2011

Prasetya, A, Kartono, dan Widodo, AT. (2012). Model IDEAL problem Solving untuk Pemcapaian Kemampuan Pemecahan Masalah di kelas Olimpiade. Jurnal Universitas Negeri Semarang: Lembaran Ilmu Kependidikan. ISSN 0216-0847. Semarang. 
Prastowo, A. (2014). Pengembangan Bahan Ajar Tematik. Jakarta: Kencana Predanamedia Group.

Prianto, Agus. (2014). Kajian Materi Aljabar dan Komunikasi Matematis. Indonesian Digital Journal of Mathematics and Education, Volume 2 Edisi 2. ISSN: 2407-7925. P4TK Matematika.

Sabandar, J. (2005). Pertanyaan Tantangan dalam Memunculkan Berpikir Kritis dan Kreatif dalamPembelajaran Matematika. Makalah Disajikan dalam Seminar Nasional, FPMIPA UPI, 20 Oktober

Santos, David A. (2004). Junior Problem Seminar. Publication License, version 1.0 or later (the latest version is presently available at http://www.opencontent.org/openpub/. [diunduh tanggal 7 Mei 2017].

Sari, Agus P., dkk. (2017). Proses Berpilir Kreatif Siswa dalam Memecahkan Masalah Matematika Berdasarkan Model Wallas. Beta Jurnal Tadris Matematika. Vol 10 No. 1.

Setiawan, D, Wahyuni, K, dan Prastati, T. (2007). Pengembangan bahan ajar. Jakarta: Universitas Terbuka.

Shoho, Alan R. (1996). A Cross Cultural Analysis of Similarities and Differences Among Math Olympads in China, Taiwan, and The United States. International Journal of Educational Research, Volume 25, Issue 6, 1996, Pages 575-582.

Sinaga, D. Yuliana. (2017). Pengaruh Model Problem Based Learning untuk Meningkatkan Kemampuan Berpikir Kreatif Siswa. Prosiding Seminar Nasional Tahunan Fakultas Ilmu Sosial Universitas Negeri Medan Tahun 2017. e-ISSN: 2549-5976, p-ISSN: 2549-435X.

Subali, B., \& Handayani, L. (2012). Pengembangan CD Pembelajaran Lagu Anak Untuk Menumbuhkan Pemahaman SAINS Siswa Sekolah Dasar. Jurnal pendidikan fisika Indonesia, 8(1)

Subotnik, R. F. Miseranclino, A. D. Olszewski-K, Paula. (1996). Implications of the Olympiad Studiesfor the Developmentof Mathematical Talent in Schools. International Journal of Educational Research, Volume 25, Issue 6, 1996, Pages 563-573.

Sugiyono. (2017). Metode Penelitian Kuantitatif, Kualitatif dan $R \& D$. Bandung. Alfabeta.

Sujadi. (2002). Metodologi Penelitian Pendidikan. Jakarta: Rineka Cipta.

Sukmadinata, N. S. (2009). Metode Penelitian Pendidikan. Bandung: Rosda Karya.

Sumartini, Tina S. (2015). Peningkatan kemampuan Penalaran Matematis Siswa Melalui Pembelajaran Berbasis Masalah. Jurnal Pendidikan Matematika Volume 5, Nomor 1, April 2015. ISSN 2086-4299.

Sunardi. (2016). Startegi Penguatan Pengembangan 4C's dalam Pembelajaran Matematika. Prosiding Seminar Nasional Pendidikan Matematika. Malang: Pascasarjana Universitas Negeri Malang

Suriasumantri, Jujun S. (1999). Filsafat Ilmu Sebuah Pengantar Populer. Jakarta: Sinar Harapan. 
Surajiyo. (2006). Dasar-dasar Logika. Jakarta: PT Bumi Aksara.

Surya, Yohanes. (2016). Seri Olimpiade Sains Matematika SMP/MTs. Jakarta: PT Olimpiade Sains Indonesia

Suryadi, D. (2005). Penggunaan Pendekatan Pembelajaran Tidak Langsung serta Pendekatan Gabungan Langsung dan Tidak Langsung dalam Rangka Meningkatkan Kemampuan Matematik Tingkat Tinggi Siswa SLTP. Disertasi Doktor pada PPS UPI: Tidak Diterbitkan.

Soekadijo. (2008). Logika Dasar: tradisional, simbolik, dan induktif. Jakarta: PT Gramedia Pustaka Utama.

Soekanto. (1993). Teori Psikologi. Jakarta: Rajawali Press, hlm. 48

Thiagarajan, Sivasailam, dkk. (1974). Instructional Development for Training Teachers of Exceptional Children. Indiana University Bloomington. National Center for Improvement of Educational Systems (DHEW/OE), Washington, D. C.

Trisnowali, Andi. (2015). Profil Disposisi Matematis Siswa Pemenang olimpiade pada Tingkat Provinsi Sulawesi Selatan. Journal of EST, Volume 1 Nomor 3 Desember 2015 hal 47-57. p-ISSN:2460-1497. e-ISSN: 2477-3840.

Tohir, Mohammad. (2013). Kumpulan Soal dan Pembahasan Olimpiade Matematika SMP. http://olimattohir.blogspot.co.id/2013/06/olimpiade-matematika.html. [diunduh tanggal 7 Mei 2017].

Tohir, Mohammad. (2016). Modul Pembinaan Olimpiade Matematika Bagi Guru-guru SMP. Disajikan pada Workshop Olimpiade Matematika Guru MGMP Matematika SMP. Kota Mojokerto, Kota Blitar, dan Kabupaten Madiun.

Tohir, Mohammad. (2016). Buku Pembinaan Olimpiade Matematika SMP/MTs. Jember: Matematohir Scientific Publishing.

Tohir, Mohammad. (2016). Buku Pengayaan UN Matematika SMP/MTs Kelas IX. Jember: Matematohir Scientific Publishing.

Tohir, Mohammad. (2016). Menjadikan Para Siswa Aktif Bertanya dalam Kelas Matematika BerdasarkanKurikulum 2013. Prosiding Seminar Nasional Matematika dan Pembelajarannya. Program Studi Pendidikan Matematika FKIP Universitas Jember, 249-263.

Tohir, Mohammad. (2016). Analisis Kemampuan Calon Guru Matematika Dalam Menerapkan Pendekatan Saintifik Berdasarkan Kurikulum 2013. Prosiding Seminar Nasional Pendidikan Matematika. Unesa Unversity Press, 431-446.

Tohir, Mohammad. (2016). Analysis of Prospective Mathematics Teachers Ability in ApplyingScientific Approach Based The Curriculum 2013. Proceedings of The National Seminar onMathematics Education 2016 at The State University of Surabaya 431-446. ISBN 978-602-449-023-2

Tohir, M. (2017). Improving Mathematical Learning Effectiveness By Using Active Learning Strategy in Aljabar Material in SMPN 2 Jember. The FKIP E-Proceeding. 
Tohir, Mohammad. (2017). Peningkatan Efektivitas Pembelajaran Matematika Dengan Menggunakan Strategi Pembelajaran Aktif Pada Materi Aljabar Di SMPN 2 Jember. Prosiding Seminar Nasional Matematika dan Pembelajarannya. Program Studi Pendidikan Matematika FKIP Universitas Jember, 39-54.

Tohir, Mohammad, Susanto, Hobri, Suharto, \& Dafik. (2018). Students' Creative Thinking Skills in Solving Mathematics Olympiad Problems Based on Problem-Solving Polya and Krulik-Rudnick Model. Advanced Science Letters, 24(11), 8361-8364.

Tohir M., Abidin Z., Dafik \& Hobri. (2018). Students creative thinking skills in solving two dimensional arithmetic series through research-based learning. Journal of Physics: Conference Series. 1008(012072).

Ulya, Izzatul dkk. (2017). Pengembangan Perangkat Pembelajaran Berdirikan Penemuan Terbimbing untuk Meningkatkan Kemampuan Penalaran Matematis Siswa pada Materi Barisan Aritmatika dan Geometri kelas X. Jurnal Kajian dan Pembelajaran Matematika. VOLUME 1 NOMOR 1, APRIL 2017. ISSN: 2549-8584.

Wardhani, Sri. (2008). Paket Fasilitas Pemberdayaan KKG/MGMP Matematika: Analisis SI dan SKL Mata Pelajaran Matematika SMP/MTs untuk Optimalisasi Tujuan Mata Pelajaran Matematika. Yogyakarta: Pusat Pengembangan Dan Pemberdayaan Pendidik Dan Tenaga Kependidikan Matematika.

Wiworo. (2004). Olimpiade Sains Nasional Matematika SMP. Disajikan pada Diklat Instruktur/Pengembangan Matematika SMP Jenjang Dasar di Pusat Pengebangan Panataran Guru Matematika (PPPG). Yogyakarta.

Wulantina, E, Kusmayadi, T.A, \& Riyadi. (2015). Proses berpikir kreatif siswa dalam pemecahan masalah matematika ditinjau dari kemampuan matematika pada siswa kelas X MIA SMAN 6 Surakarta. Jurnal Elektronik Pembelajaran Matematika. 3 (6), 671-682.

Yohanes, R. S. (2016). Upaya Meningkatkan Kemampuan Memecahkan Masalah Matematika Tim Olimpiade Matematika SMP Negeri 01 Madiun dengan Menggunakan Model Pemecahan Masalah. Seminar Nasional dan Pendidikan Matematika. ISBN. 978602-73403-1-2. Universitas Negeri Yogyakarta. 